\title{
A Diagnosis of a Long-Lasting Blocking Event over the Southeast Pacific Ocean
}

\author{
R. F. C. Marques and V. Brahmananda RaO \\ Instituto Nacional de Pesquisas Espaciais, São José dos Campos, Sao Paulo, Brazil
}

(Manuscript received 16 September 1997, in final form 10 August 1998)

\begin{abstract}
A long-lasting blocking event occurred over the southeast Pacific Ocean near the west coast of South America from 29 July through 14 August 1986. This blocking happened in a recently found new region of blocking in the southeast Pacific. During the blocking event the transient eddies were forced to move to the north and south of the blocking. This caused precipitation over South America to increase to the north of the blocking high and diminish over southern South America.

The blocking event is analyzed in detail and its impact on the winter general circulation is discussed. Change in amplitude of several wavenumbers and the zonal wind (zero wavenumber) suggest that the blocking event is essentially a local phenomenon. Since transient eddies are prevented from moving through the blocking high the variance of meridional wind is small. However, the variance of geopotential height is maximized because of the persistence of the block. This signature of the blocking on the general circulation is similar to what is seen over the New Zealand region. Calculation of local Eliassen-Palm flux showed that in the region of the split jet both the barotropic and baroclinic components complement each other to decelerate the westerlies and maintain the block. This seems to fit into the "eddy straining" concept. The principal difference between blocking over the southeast Pacific and the New Zealand regions is in barotropic energy exchange between the eddies and zonal flow. In the present case eddies maintain two branches of the jet (subtropical and subpolar) by converting eddy kinetic energy into zonal kinetic energy. At the location of the split jet, zonal kinetic energy is converted into eddy kinetic energy, thus maintaining the split jet. A composite of four blocking events over the southeast Pacific confirmed these results. This is opposite to what was found for a blocking episode near New Zealand.
\end{abstract}

\section{Introduction}

The phenomenon of atmospheric blocking still remains as one of the poorly understood problems in meteorology despite several studies performed since the early investigations of Elliot and Smith (1949) and Rex (1950a,b). This lack of understanding prevents skillful operational medium-range weather forecasting of blocking events (Tibaldi and Molteni 1990; Tibaldi et al. 1994). The situation in the Southern Hemisphere (SH) is even worse because of poor data coverage that introduces large initial errors. A good knowledge of observed aspects of blocking in the $\mathrm{SH}$ is necessary before an attempt at numerical forecasting is made.

One of the early studies of blocking in the SH was done by van Loon (1956). He used 5 yr of synoptic charts from 1 July 1950 through 30 June 1955 to study blocking in the $\mathrm{SH}$. He found three regions of blocking:

Corresponding author address: Dr. V. Brahmananda Rao, INPE, C.P. 515, São José dos Campos, São Paulo 12201-970, Brazil. E-mail: vbrao@met.inpe.br in the southwest Pacific and to the southeast of Australia, in the southwest Atlantic, and the southwest Indian Ocean. Taljaard (1972) described synoptic characteristics of blocking anticyclones in the SH. Blocking in the Austral-Asian region has been documented by Wright (1974) and Baines (1983). Coughlan (1983) compared blocking in both the hemispheres. Lejenas (1984) used 8 yr (24 April 1972-30 November 1980) of 500-hPa geopotential height analyses to discuss blocking in the SH. Trenberth and Mo (1985) studied blocking in the SH for the period May 1972-November 1980. They found that the principal location of blocking in the SH is the New Zealand sector. Berbery and Nuñez (1989) made an observational and numerical study of blocking episodes near South America. They concluded that blocking episodes can result from a local resonance between Rossby waves generated by the Andes Mountains and an upstream forcing as suggested by Kalnay-Rivas and Merkine (1981).

In a recent study, Sinclair (1996) used 10 yr (198089) of European Centre for Medium-Range Weather Forecasts (ECMWF) analyses to obtain a climatology of blocking in the $\mathrm{SH}$. He found a new region of block- 
ing in the Pacific near southwest South America. Marques (1996) used a longer series of ECMWF data (14 yr, 1980-93) and confirmed the new region of blocking in the SH, identifying blocking by a different methodology. In her climatological study Marques (1996) found a long-lasting blocking event of 17 days (29 July14 August 1986) in this new region of blocking, namely, southwest South America. The purpose of the present paper is to study this blocking event, addressing and discussing the following questions: 1) What are the similarities and differences between the blocking event over the southeast Pacific and those that occur in the wellknown region of blocking in the New Zealand region? 2) What are the effects of blocking in this region on the winter general circulation over the SH? 3) What is the effect of blocking in this region on precipitation over South America?

\section{Data sources and methodology}

In the present study we used ECMWF data at 1200 UTC for the period June, July, and August 1986. We used geopotential height, zonal wind, meridional wind, and temperature data at various pressure levels. The ECMWF analysis was produced by a data assimilation system run as an intermitent 6-h analysis-initializationforecast cycle. A review of this data assimilation was given by Bengtsson (1986). A 6-h forecast from the previously initialized analysis provides the first guess. The first guess is updated using observations from all sources that are made within $3 \mathrm{~h}$ of observation time. The data are then archived on a $2.5^{\circ} \times 2.5^{\circ}$ (latitudelongitude) grid. For further details about the ECMWF data see Trenberth and Olson (1988). Although the southeast Pacific has relatively few conventional observations (Hollingsworth et al. 1986), use of remotely sensed data and drifting buoys improves the analysis. Further, a large block is probably hard to miss by any analysis. In this study we propose to verify the effect of the block over the southeast Pacific on rainfall over southern South America. Rainfall data for August 1986 are taken from World Meteorological Organization (1986).

We also propose to prepare latitude-pressure cross sections of zonal wind for the eastern Pacific. This will help us to discern whether the bifurcation of the jet is a mean winter feature in the region or not. For this purpose, we use monthly mean zonal wind data taken from the National Centers for Environmental Prediction-National Center for Atmospheric Research reanalysis for the period 1982-94 (Kalnay et al. 1996).

In this study we used the methodology developed by Lejenäs and Okland (1983) and Lejenäs (1984) to identify blocking in the SH. Just as in Lejenäs and Madden (1992), the data were subjected to a Fourier analysis along each latitude and the first 18 zonal harmonics were
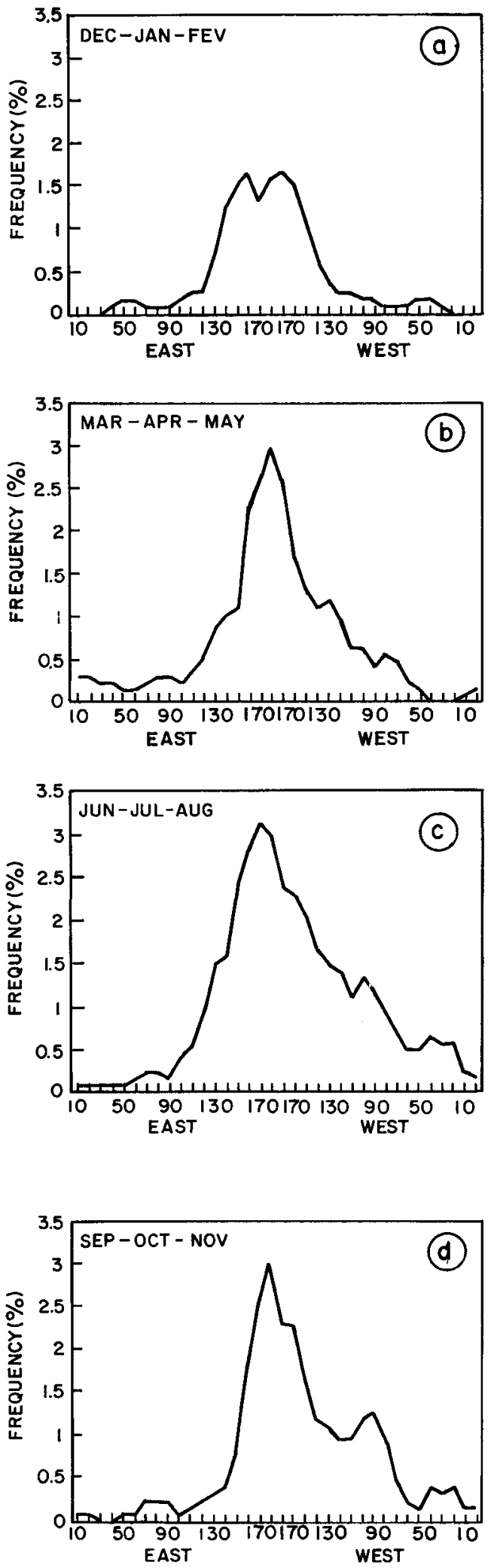

FIG. 1. Longitudinal variation of blocking frequency for the period 1980-93 for (a) summer (Dec, Jan, and Feb), (b) autumn (Mar, Apr, and May), (c) winter (Jun, Jul, and Aug), and (d) spring (Sep, Oct, and Nov). 


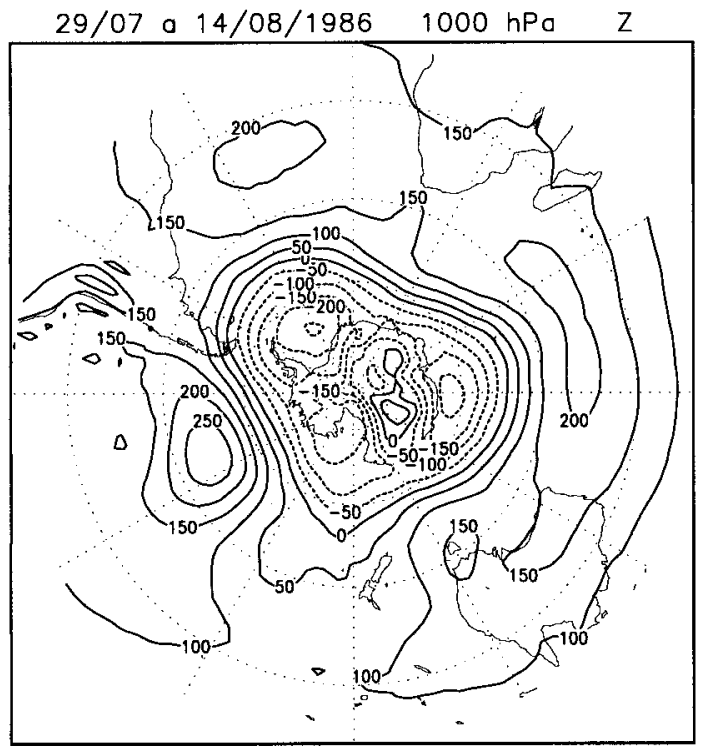

a

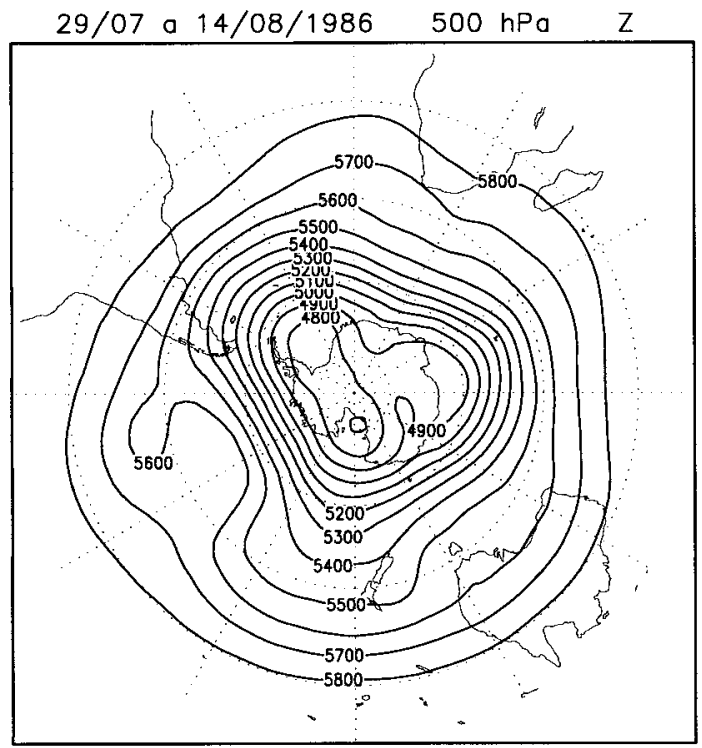

b

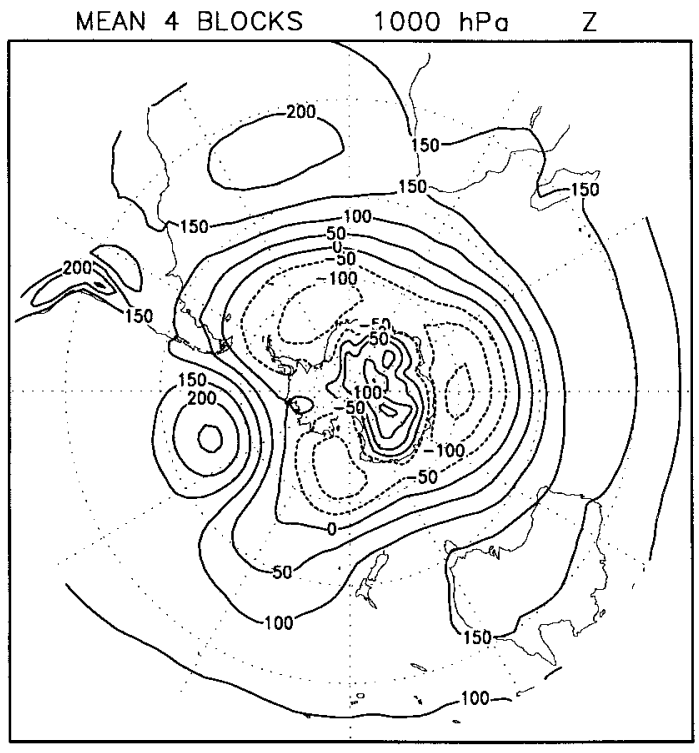

C

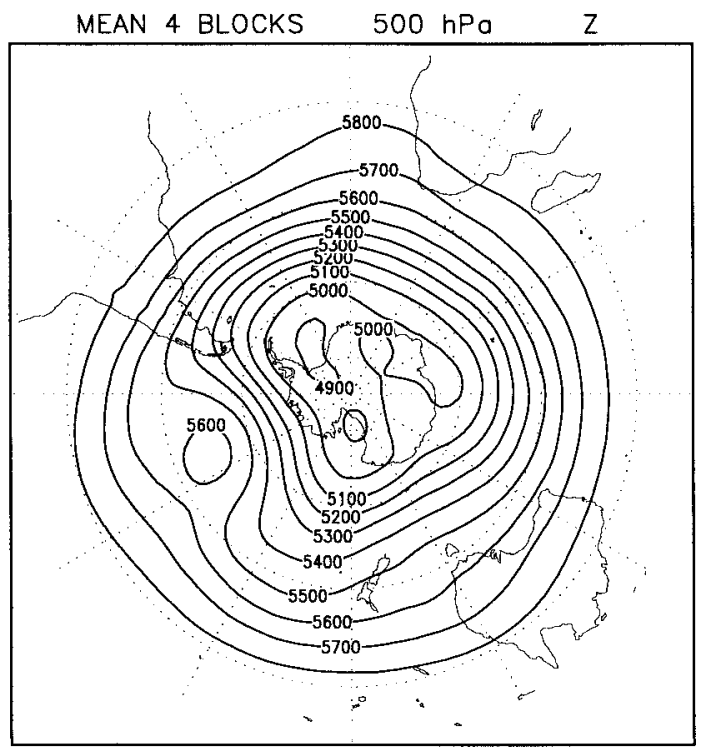

d

FIG. 2. Distribution of mean geopotential height (in gpm) for the period 29 Jul-14 Aug 1986 at (a) 1000 and (b) $500 \mathrm{hPa}$, and for the composite of four blocks: (c) 1000 and (d) $500 \mathrm{hPa}$.

retained. This ensures removal of waves shorter than $20^{\circ}$ longitude.

In view of the earlier works on blocking in the $\mathrm{SH}$ by van Loon (1956), Taljaard (1972), Wright (1974), Coughlan (1983), and Trenberth and Swanson (1983), Lejenäs defined an index ( $I$ ) for the 500 -hPa geopo- tential height difference between $35^{\circ}$ and $50^{\circ} \mathrm{S}$ at longitude $\lambda$ :

$$
I(\lambda)=Z_{35^{\circ} \mathrm{S}}(\lambda)-Z_{50^{\circ} \mathrm{S}}(\lambda)
$$

$I(\lambda)$ is calculated for each $10^{\circ}$ longitude interval. The 


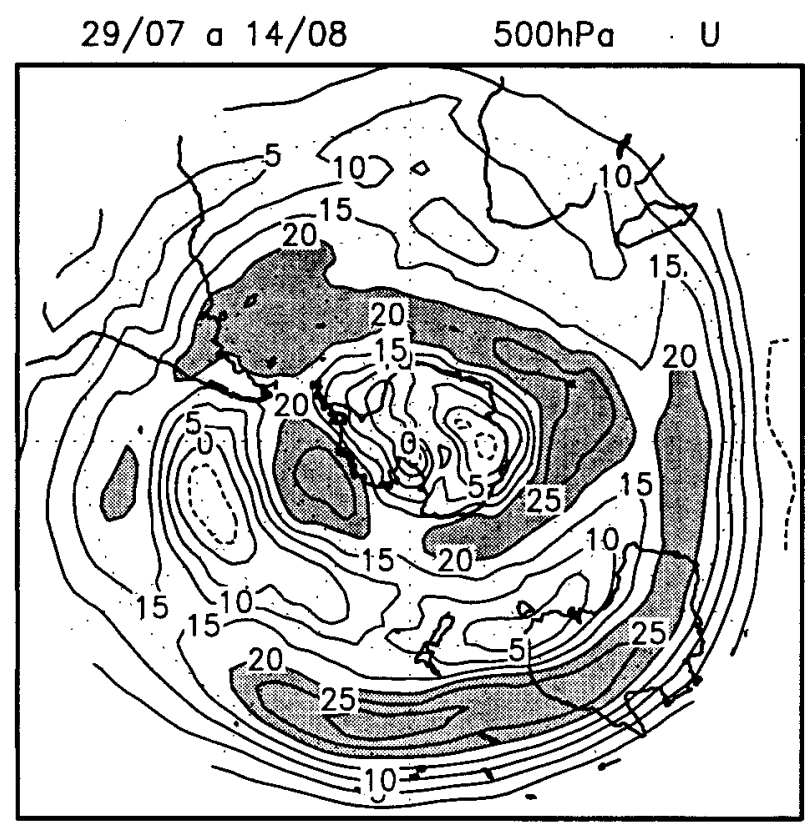

FIG. 3. Distribution of mean zonal wind (in $\mathrm{m} \mathrm{s}^{-1}$ ) for the period 29 Jul-14 Aug 1986 at $500 \mathrm{hPa}$.

situation of blocking should satisfy the following conditions:

$$
\begin{aligned}
I(\lambda) & <0 \\
{[I(\lambda-10)+I(\lambda)+I(\lambda-10)] / 3 } & <0 .
\end{aligned}
$$

Condition (3) ensures that blocking occurs over at least $30^{\circ}$ longitude. Conditions (2) and (3) also guarantee the

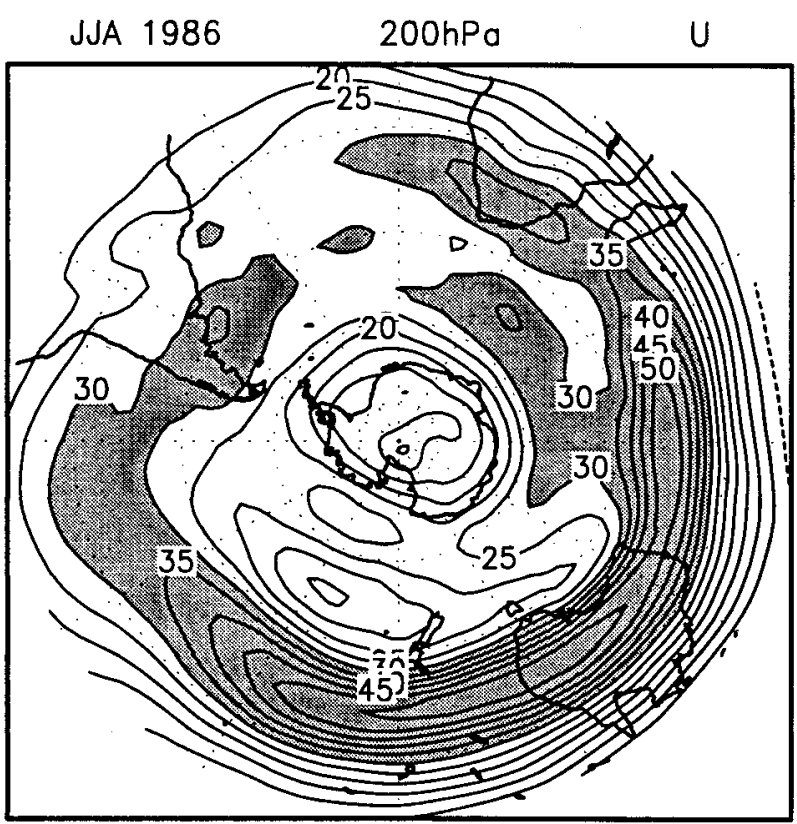

FIG. 4. Distribution of mean zonal wind (in $\mathrm{m} \mathrm{s}^{-1}$ ) for the winter season of 1986 at $200 \mathrm{hPa}$.

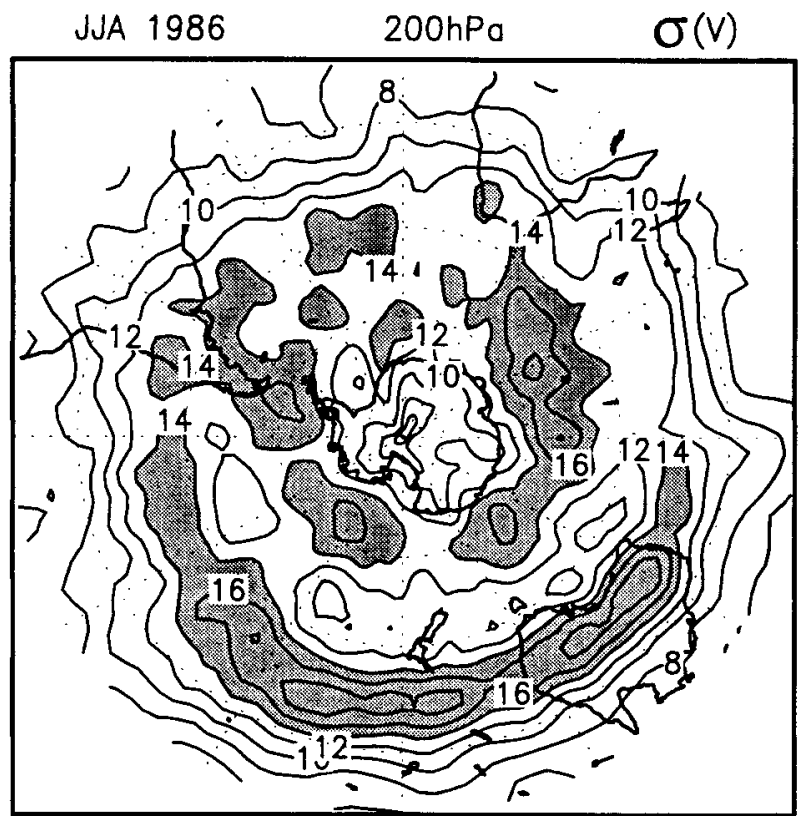

FIG. 5. Standard deviation of meridional wind, $\sigma(v)$ (in $\mathrm{m} \mathrm{s}^{-1}$ ), for the winter season of 1986 at $200 \mathrm{hPa}$.

occurrence of blocks, which are generally persistent. However, a longevity requirement of a minimum persistence of 3 days is adapted.

In the present study we also verify the role of barotropic energy interactions. Trenberth (1986a) suggested that barotropic energy interactions are important during blocking episodes. The barotropic energy conversion term is given by

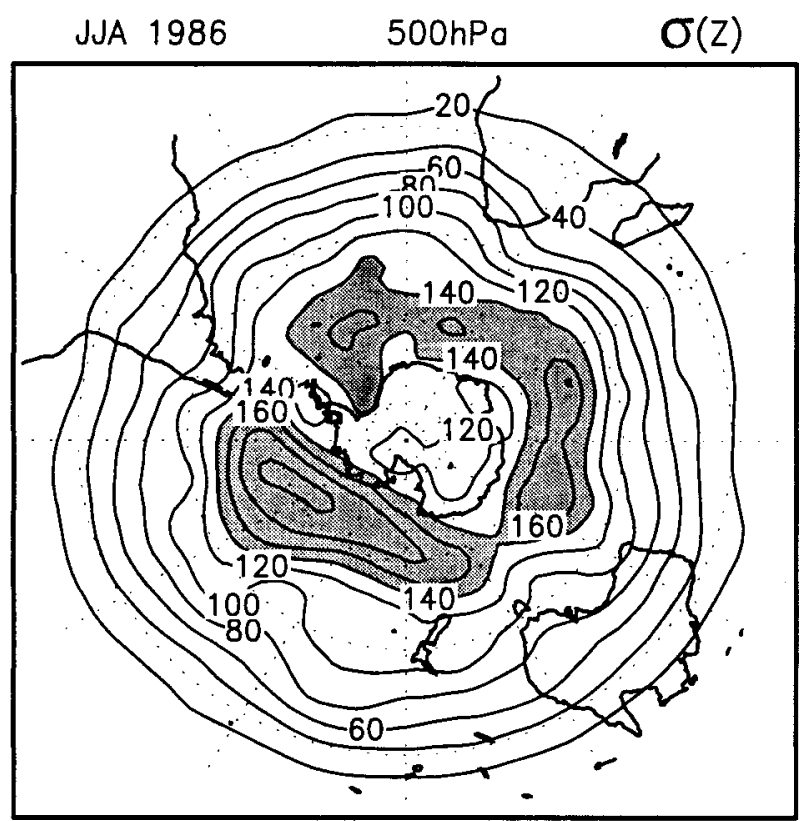

FIG. 6. Standard deviation of geopotential height, $\sigma(z)$ (in gpm), for the winter season of 1986 at $500 \mathrm{hPa}$. 
TABle 1. Rainfall anomalies over South America, Aug 1986.

\begin{tabular}{|c|c|c|c|c|c|c|c|}
\hline \multirow[b]{3}{*}{ Station } & \multirow{3}{*}{$\begin{array}{l}\text { Lat } \\
\left({ }^{\circ} \mathrm{S}\right)\end{array}$} & \multirow{3}{*}{$\begin{array}{l}\text { Long } \\
\left({ }^{\circ} \mathrm{W}\right)\end{array}$} & \multirow{3}{*}{$\begin{array}{l}\text { Elev } \\
(\mathrm{m})\end{array}$} & \multicolumn{4}{|c|}{ Rainfall (mm) } \\
\hline & & & & \multicolumn{4}{|c|}{ Aug 1986} \\
\hline & & & & Normal & Total & Departure & Departure (\%) \\
\hline Rivadavia & 24.10 & 62.54 & 205 & 7 & 29 & +22 & +314.3 \\
\hline Ilha De Pascoa & 27.10 & 109.26 & 69 & 90 & 117 & +27 & +30 \\
\hline Cordoba Aero & 31.19 & 64.13 & 474 & 15 & 21 & +6 & +40 \\
\hline Quintero & 32.47 & 71.31 & 2 & 58 & 75 & +17 & +29.3 \\
\hline Punta Angeles & 33.01 & 71.39 & 41 & 58 & 77 & +19 & +32.7 \\
\hline Rio Cuarto & 33.07 & 64.14 & 421 & 17 & 21 & +4 & +23.5 \\
\hline I. Robinson Crusoe & 33.37 & 78.50 & 30 & 117 & 178 & +61 & +52.1 \\
\hline Villa Reynolds & 33.44 & 65.23 & 484 & 14 & 22 & +8 & +57.1 \\
\hline Pigue & 37.36 & 62.23 & 304 & 20 & 66 & +46 & +230 \\
\hline Bahia Blanca & 38.44 & 62.11 & 83 & 20 & 64 & +44 & +220 \\
\hline Valdivia & 39.38 & 73.05 & 19 & 283 & 298 & +15 & +5.3 \\
\hline St. Antonio Oeste & 40.44 & 64.57 & 7 & 16 & 6 & -10 & -62.5 \\
\hline Bariloche & 41.09 & 71.10 & 840 & 125 & 103 & -22 & -17.6 \\
\hline Puerto Montt & 41.26 & 73.06 & 90 & 201 & 142 & -59 & -29.3 \\
\hline Esquel & 42.56 & 71.09 & 785 & 61 & 18 & -43 & -70.5 \\
\hline Ilha Guafa & 43.34 & 74.44 & 140 & 192 & 71 & -121 & -63 \\
\hline C. Rivadavia & 45.47 & 67.30 & 46 & 21 & 12 & -9 & -42.8 \\
\hline Puerto Deseado & 47.44 & 65.55 & 79 & 17 & 2 & -15 & -88.2 \\
\hline Governador Gregores & 48.47 & 70.10 & 358 & 12 & 7 & -5 & -41.7 \\
\hline San Julian & 49.19 & 67.45 & 62 & 22 & 6 & -16 & -72.7 \\
\hline Sta. Cruz & 50.01 & 68.34 & 111 & 14 & 10 & -4 & -28.6 \\
\hline Lago Argentino & 50.20 & 72.18 & 220 & 23 & 5 & -18 & -78.3 \\
\hline Rio Gallegos & 51.37 & 69.19 & 17 & 13 & 6 & -7 & -53.8 \\
\hline P. Arenas & 53.00 & 70.51 & 44 & 39 & 4 & -35 & -89.7 \\
\hline
\end{tabular}

$$
C\left(k^{\prime}, \bar{k}\right)=-\int U \frac{\partial}{\partial y} \overline{u^{\prime} v^{\prime}} d y,
$$

where $k^{\prime}$ is the eddy kinetic energy, $\bar{k}$ is the zonal kinetic energy, $\overline{u^{\prime} v^{\prime}}$ is the eddy momentum transport, $\overline{(\bullet)}$ is the time mean, and $(\bullet)^{\prime}$ is the time deviation. In addition, $U$ is the time and zonal mean taken over the period of the blocking (29 July-August 1986) and over the region $75^{\circ}-165^{\circ} \mathrm{W}$. Thus, in the region where there is divergence of momentum transport associated with positive values of $U$, the zonal kinetic energy is converted into eddy kinetic energy or eddies gain kinetic energy from the zonal wind. The reverse happens if there is a convergence of momentum transport.

A useful measure of upper-tropospheric transient eddies is the extended Eliassen-Palm (E-P) flux, which was originally developed by Hoskins et al. (1983) and Plumb (1986), and modified by Trenberth (1986b), so that it will not be subject to restrictions arising from geostrophic or other approximations. In three dimensions, the localized Eliassen-Palm vector is

$$
E=\left[\frac{1}{2}\left(\bar{v}^{\prime 2}-\bar{u}^{\prime 2}\right),-\overline{u^{\prime} v^{\prime}}, f \frac{\overline{v^{\prime} \Phi_{z}^{\prime}}}{S}\right] \cos \phi,
$$

where $V=(u, v)$ is the horizontal velocity vector, $\phi$ is the latitude, and $\Phi$ is the geopotential. With this definition of $E$, the effects of eddies on the zonal mean flow is such that

$$
\frac{\partial}{\partial t} \bar{u} \cos \phi=\nabla \cdot E
$$

where $\boldsymbol{\nabla}$ is the three-dimensional divergence operator. Therefore, the divergence of the Eliassen-Palm flux can be interpreted as the transient eddy forcing on the westerly mean flow. With this definition the relative group velocity of the transient wave is parallel to $E$. In Eq. (5), the horizontal component is the barotropic part and the vertical component is the baroclinic part.

\section{The blocking event of 29 July-14 August 1986}

Using the methodology mentioned in section 2, Marques (1996) identified blocks in the 14 yr (198093) of the ECMWF dataset. Figure 1 shows the frequency (percentage of the total number of days) of blocks in the $\mathrm{SH}$ for the four seasons as a function of longitude. It can be seen that the principal region of blocking is around New Zealand $\left(180^{\circ}\right)$. However, a secondary peak is seen over the eastern Pacific around $90^{\circ}-100^{\circ} \mathrm{W}$ during the winter and spring seasons. This result updates the study of Lejenäs (1984) and confirms the finding of Sinclair (1996).

The blocking event of 17-day duration occurred from 29 July through 14 August 1986 over the southeast Pacific. Blocking events of 17 days are not common in the Southern Hemisphere (Lejenäs 1984; 


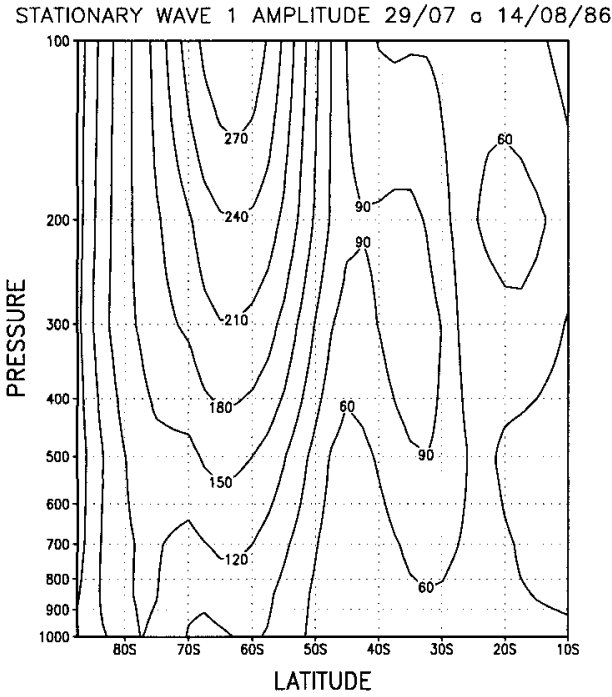

a

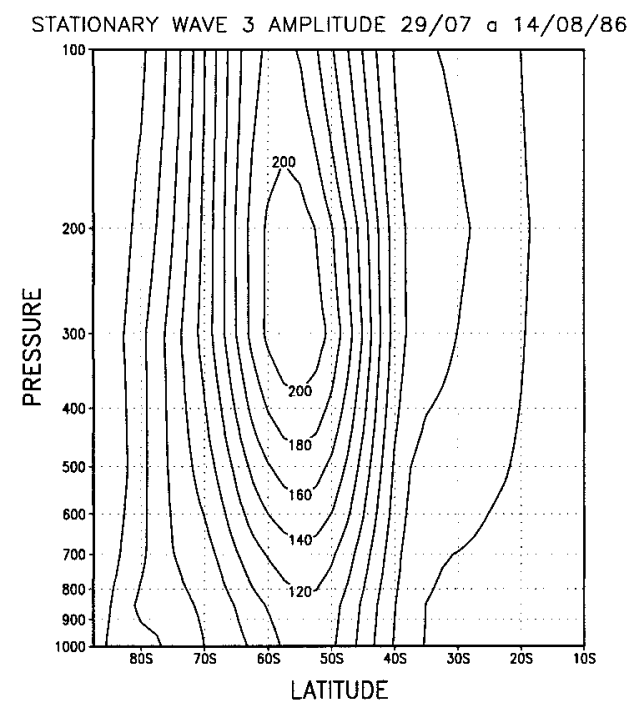

C

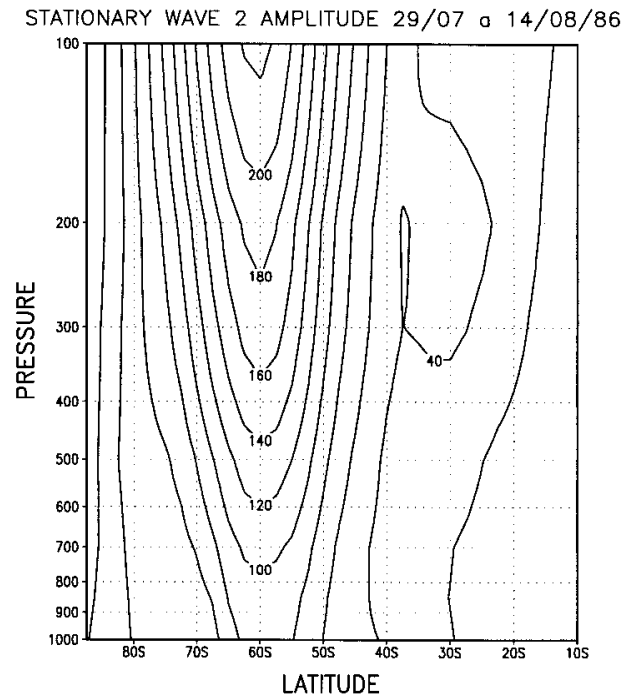

$b$

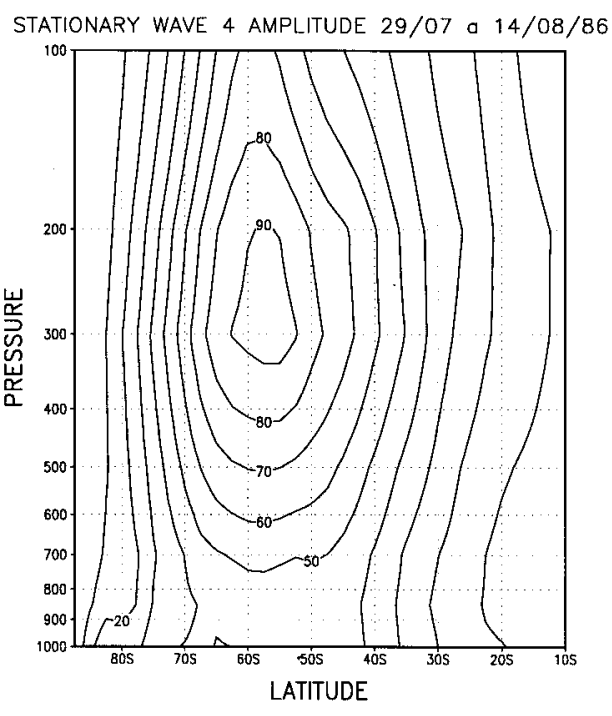

d

FIG. 7. Stationary wave amplitude (in gpm) for the period 29 Jul-14 Aug 1986 for (a) stationary wave 1, (b) stationary wave 2 , (c) stationary wave 3 , and (d) stationary wave 4.

Marques 1996). Figure 2 shows the 17-day mean geopotential height at $1000 \mathrm{hPa}$ (Fig. 2a) and at $500 \mathrm{hPa}$ (Fig. 2b). A strong blocking high can be seen in the southeast Pacific near the west coast of South America at $1000 \mathrm{hPa}$. The signature of the blocking high is very clear at $500 \mathrm{hPa}$, with an inverted omega $(\Omega)$ type configuration similar to Fig. 1.66 of Bluestein (1993). Also, the dominance of wavenumber 3 can be seen in the middle and high latitudes both at 1000- and 500$\mathrm{hPa}$ levels.

In order to examine the mean structure of blocking over the southeast Pacific, a composite of four blocking 


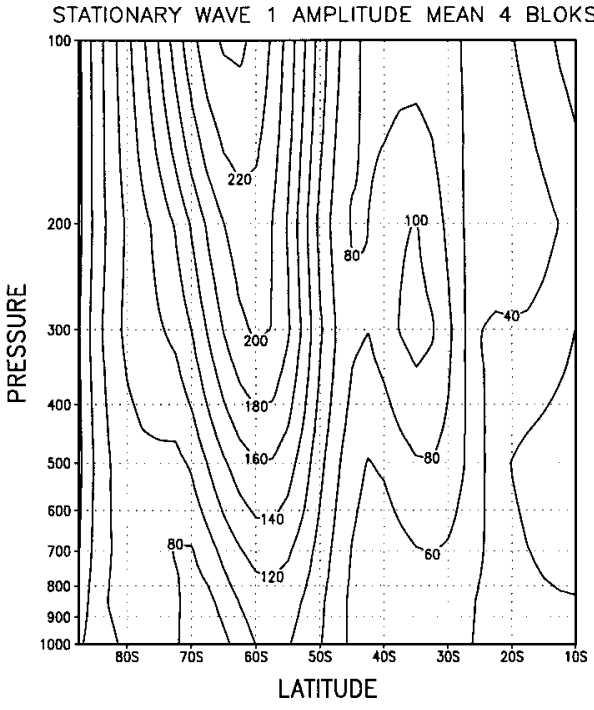

a

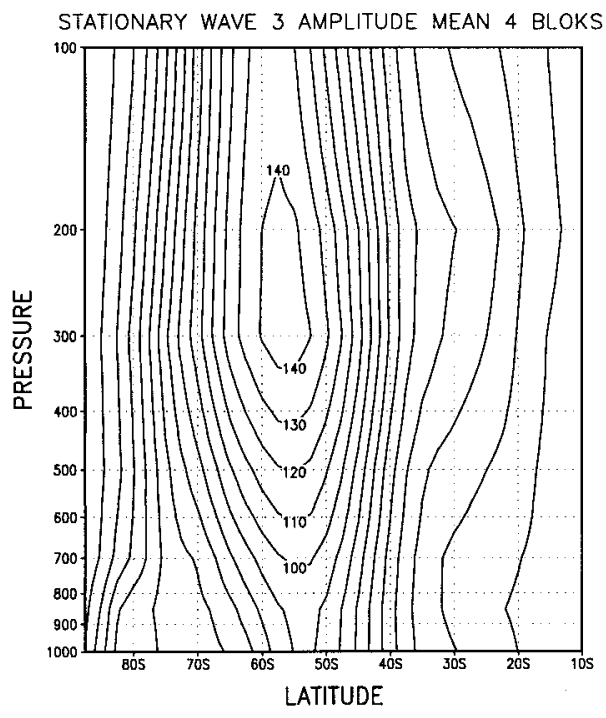

c

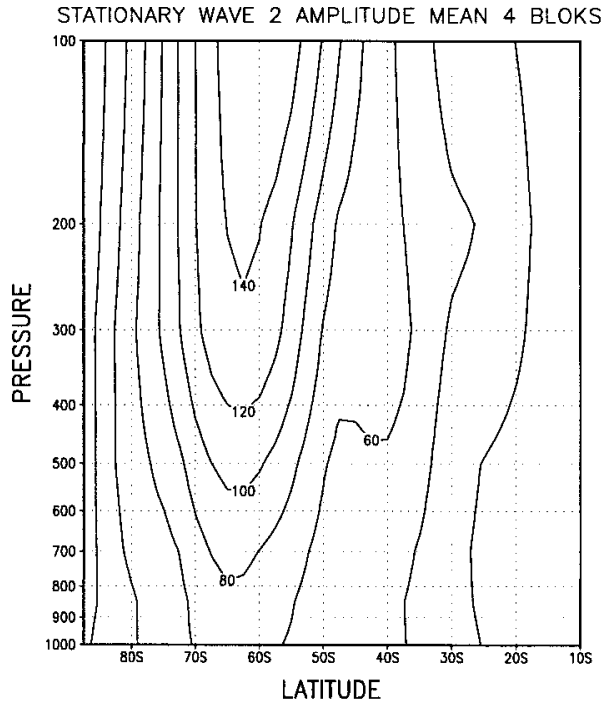

$b$

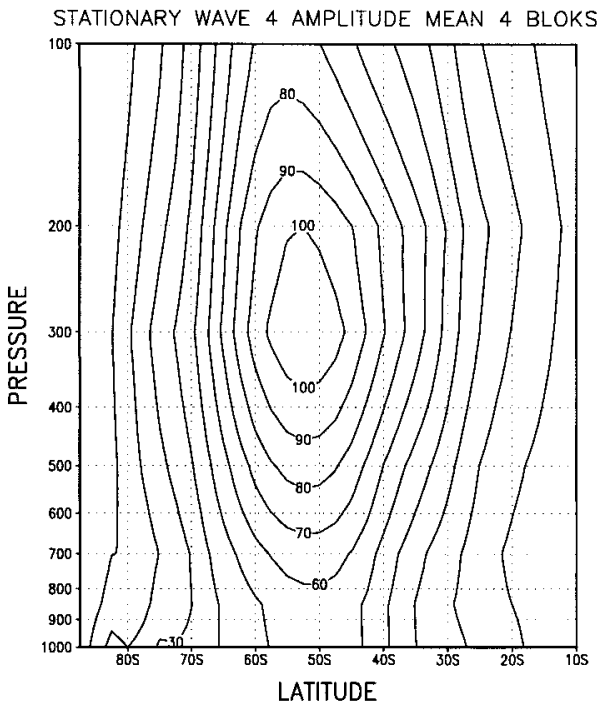

d

FIG. 8. Same as Fig. 7 but for the composite of four blocking events.

episodes of relatively longer duration in this region (29 July-14 August 1986, 5-16 July 1987, 20-28 August 1988, and 18-26 June 1992) is prepared. Figures 2c and $2 \mathrm{~d}$ show, respectively, the geopotential height at $1000 \mathrm{hPa}$ and $500 \mathrm{hPa}$ for the composite. Also in this composite the signature of the blocking high is very clear. Even in the composite the dominance of wavenumber 3 can be seen in the higher latitude of the $\mathrm{SH}$.

Figure 3 shows the zonal wind at $500 \mathrm{hPa}$ for the period 29 July-14 August 1986. In the region of the blocking anticyclone in the southeast Pacific, one can note weak westerly winds with easterlies in the center. 


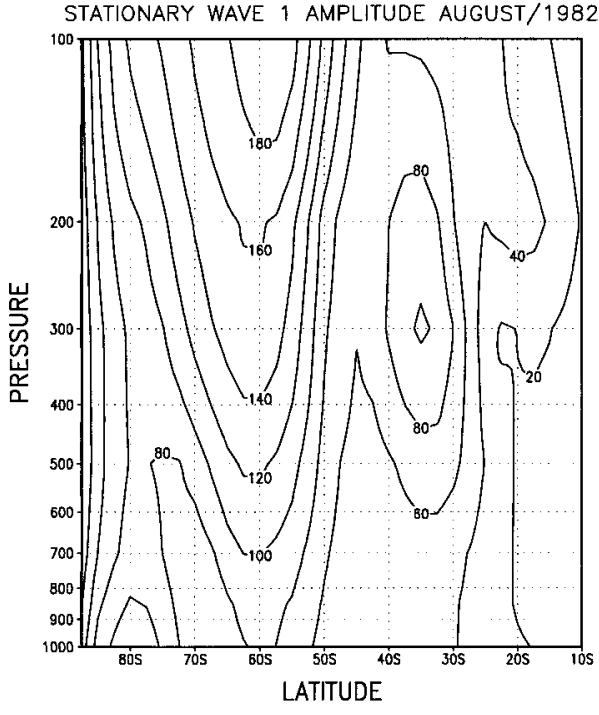

a

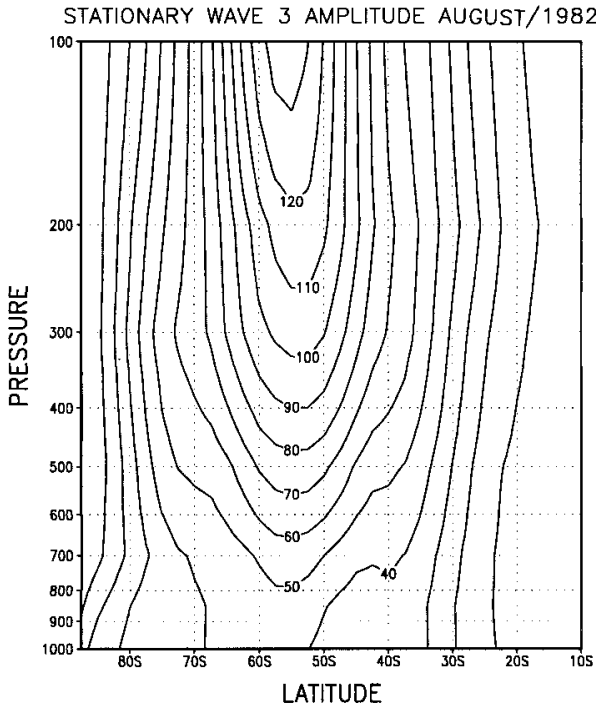

C

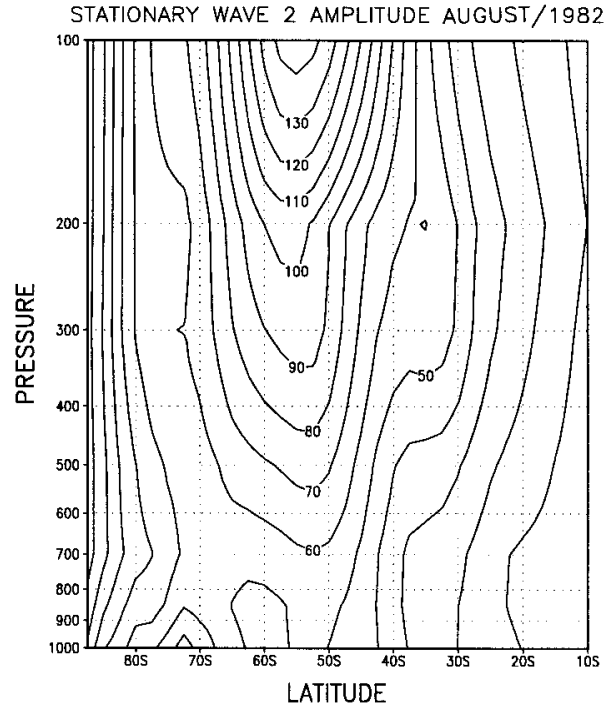

b

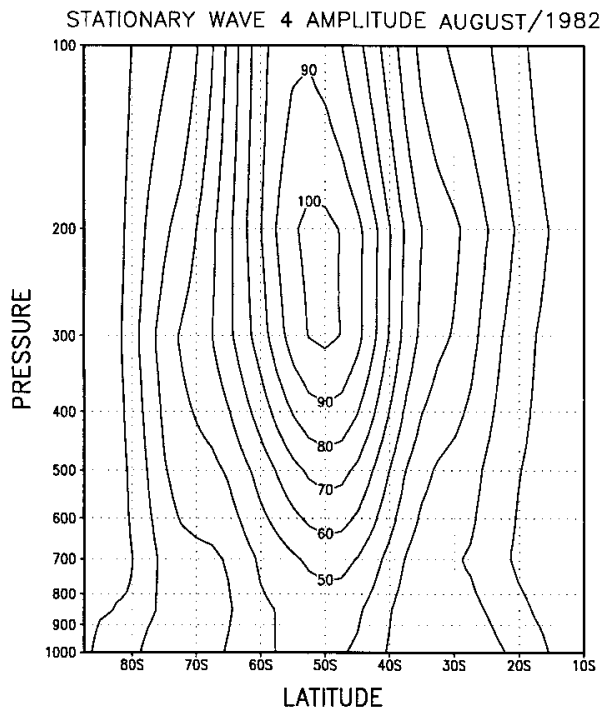

d

Fig. 9. Same as Fig. 7 but for Aug 1982.

This is a characteristic of blocking detected through zonal index as mentioned by Lejenäs and Okland (1983).

To examine the mean winter 1986 characteristics, we prepared Fig. 4, which shows the mean [June, July, and August (JJA) 1986] 200-hPa zonal wind compo- nent. This figure shows a double-jet structure in the SH. Figure 5 shows the standard deviation of meridional wind for daily values at $200 \mathrm{hPa}$ for the winter season (JJA) of 1986. By comparing these two figures (Figs. 4 and 5), it can be noted that the maximum eddy activity closely follows the jet maximum, tending to 

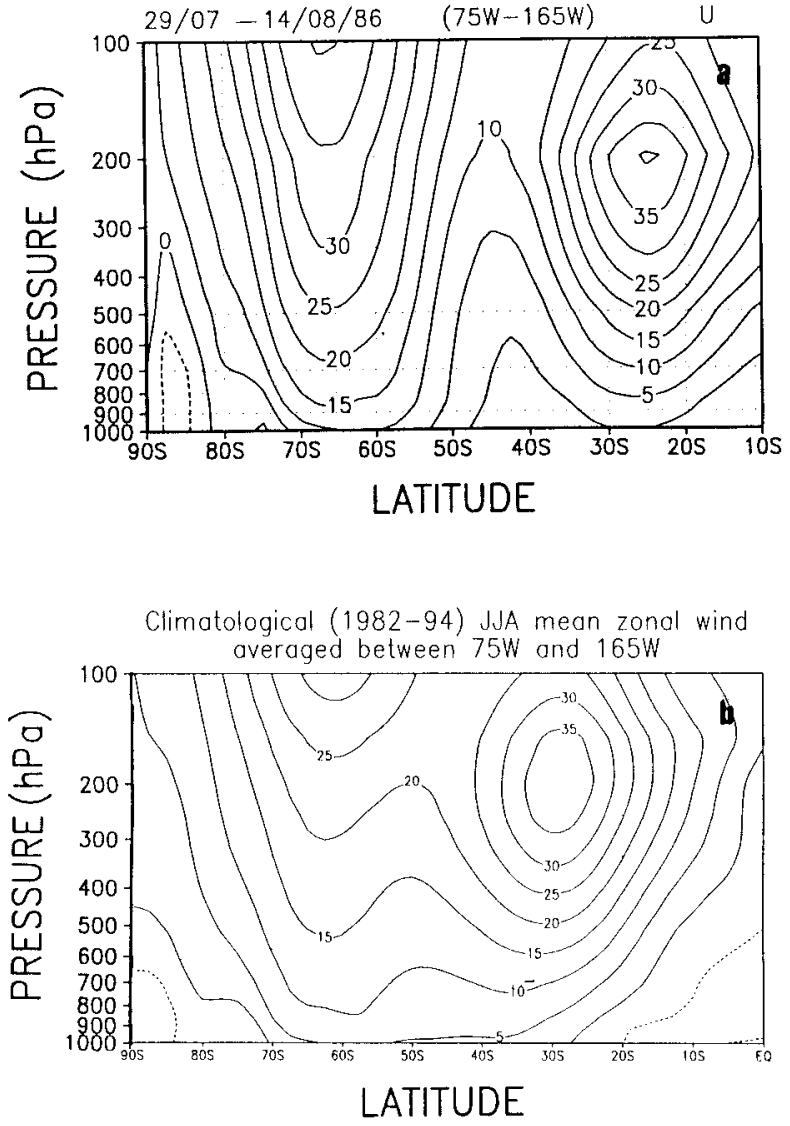

FIG. 10. Vertical distribution of mean zonal wind $(U)$ (in $\mathrm{m} \mathrm{s}^{-1}$ ) for longitude belt $75^{\circ}-165^{\circ} \mathrm{W}$, (a) for the period 29 Jul-14 Aug 1986 and (b) for climatology (1982-94).

spiral into the higher latitudes from about $30^{\circ} \mathrm{S}$ over Australia to about $60^{\circ} \mathrm{S}$ south of New Zealand. Also, another important feature brought out in Fig. 5 is the break in the eddy activity of the "storm track" around $120^{\circ} \mathrm{W}$ and $50^{\circ} \mathrm{S}$ in the region of the blocking high.

Figure 6 shows the standard deviation of the 500$\mathrm{hPa}$ geopotential height, for daily values for the winter season, $\sigma(z)$. Note the maximum of $\sigma(z)$ in the region of minimum $\sigma(v)$ noted in Fig. 5. As noted by Trenberth (1986b), the characteristic signature of the blocking events is the coincidence of maximum $\sigma(z)$ with minimum $\sigma(v)$. This is in marked contrast to what happens in a normal storm track (see Fig. 3 of Trenberth 1986b). A comparison of Figs. 4 and 6 shows the changes in storm track during the blocking event of 1986, and these changes caused anomalous weather conditions in this region, with generally dry weather under the influence of the blocking high and rainy conditions to the north. Table 1 shows the rainfall anomalies over South America. The last column of Table 1 shows the percentage of departure from the normal (mean of the period 1951-80). Generally (positive rainfall anomalies) wet conditions prevailed to the north of the blocking high and negative rainfall anomalies occurred in the region of the blocking high. At some stations the rainfall anomalies are quite high. This shows the influence of blocking in this region on precipitation over South America. Rutllant and Fuenzalida (1991) also found that the blocking events over the southeast Pacific $\left(90^{\circ} \mathrm{W}\right)$ were associated with higher rainfall over Santiago $\left(33.5^{\circ} \mathrm{S}\right)$, Chile.

In order to see the wavenumber composition of a blocking event in the southeast Pacific, Fig. 7 shows the wavenumber breakdown for the 1986 blocking event. Figure 8 shows the mean wavenumber composite for the same four blocking events mentioned earlier. Figure 9 shows the wavenumber breakdown during August 1982 when no blocking occurred, thus representing the normal winter characteristics. During the blocking event of 1986 the amplitude of wave 1 became much higher [around 270 geopotential meters $(\mathrm{gpm})$ at $65^{\circ} \mathrm{S}$ ] in the upper troposphere compared to the values during the normal winter $\left(180 \mathrm{gpm}\right.$ at $\left.60^{\circ} \mathrm{S}\right)$. The values of secondary maxima in the upper troposphere around $35^{\circ} \mathrm{S}$ are also high during the blocking event. The amplitude of wave 3 is almost double during the blocking event compared to its amplitude during the normal winter. Another interesting difference in wave 3 is that the maximum value is confined to the upper troposhere whereas in the normal winter it propagates to the lower stratosphere. A comparison of Fig. 7 and Figs. 14 and 16 of Trenberth (1986a) shows that in the present case of blocking in the southeast Pacific the amplitudes are much higher for waves 1,2, and 3 than those during the blocking in the New Zealand region. In particular, the amplitudes of waves 2 and 3 were much larger in the present case. Characteristics similar to that of 1986 are also seen in the composite of the four blocking events (Fig. 8). This shows that the characteristics of the 1986 events are also seen in the other southeast Pacific events.

\section{Physical mechanisms associated with the southeastern Pacific blocking}

In this section we shall analyze the physical mechanisms involved in the blocking event, particularly the role of eddies on the onset and maintenance of blocking. Figure 10a shows the vertical cross section of zonal wind averaged between $75^{\circ}$ and $165^{\circ} \mathrm{W}$ encompassing the blocking high (see Fig. 2) for the period 29 July14 August 1986. A clear double-jet structure with westerly winds exceeding $30 \mathrm{~m} \mathrm{~s}^{-1}$ can be seen. Another important characteristic of Fig. 10a is the strong horizontal and vertical shears. This shows that both barotropic and baroclinic effects might be important in the present blocking event. The split in the westerly jet is known to occur near New Zealand even in the mean flow and this favors blocking in this region (Trenberth and Mo 1985). The split jet structure also occurred over 


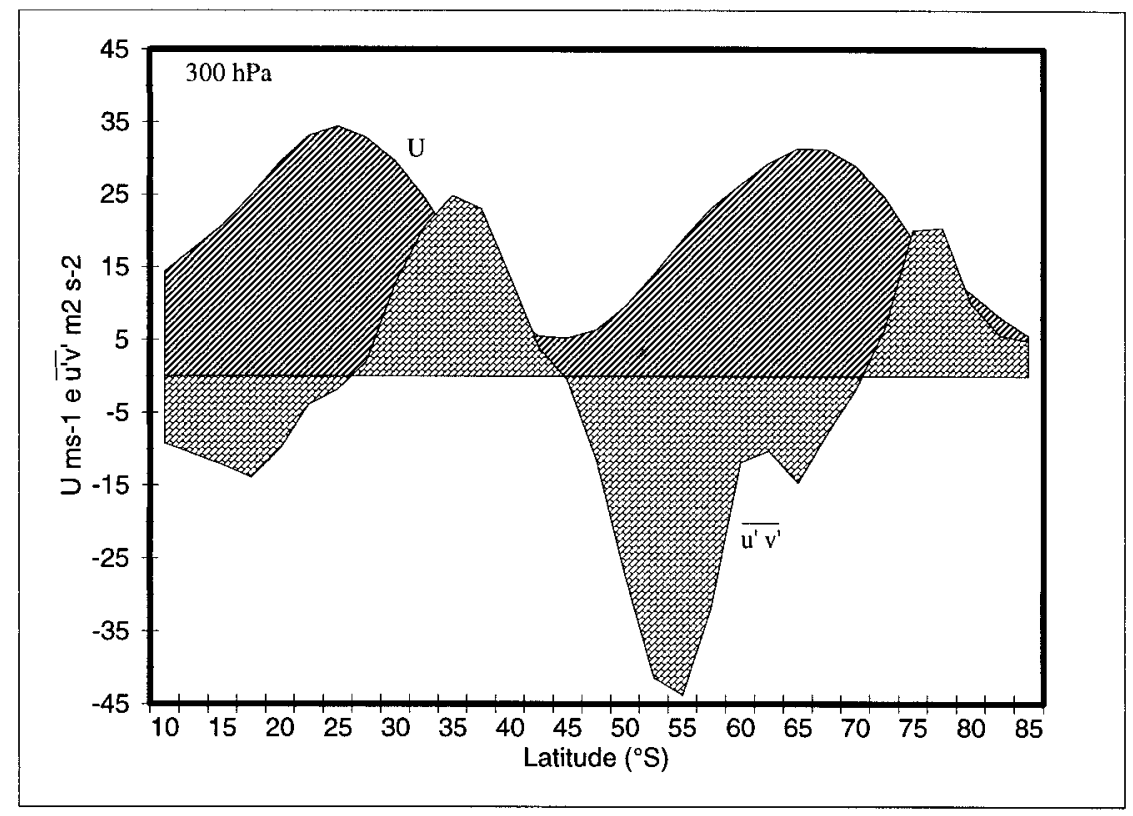

a

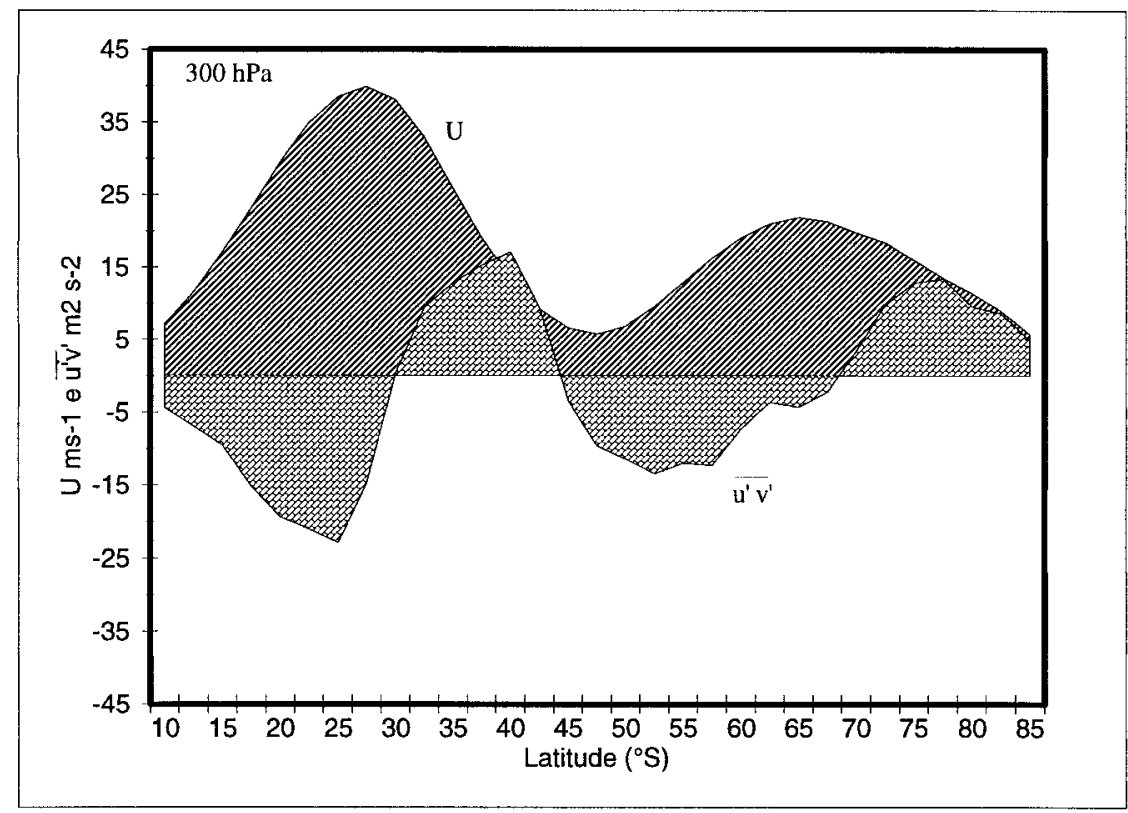

b

FIG. 11. Distribution of mean zonal wind $(U)$ (in $\mathrm{m} \mathrm{s}^{-1}$ ) and momentum flux $\left(\overline{u^{\prime} v^{\prime}}\right)$ (in $\mathrm{m}^{2} \mathrm{~s}^{-2}$ ) at $300 \mathrm{hPa}$, for the longitude belt $75^{\circ}-165^{\circ} \mathrm{W}$, for (a) the period $29 \mathrm{Jul}-14$ Aug 1986 and (b) the composite of four blocks. 

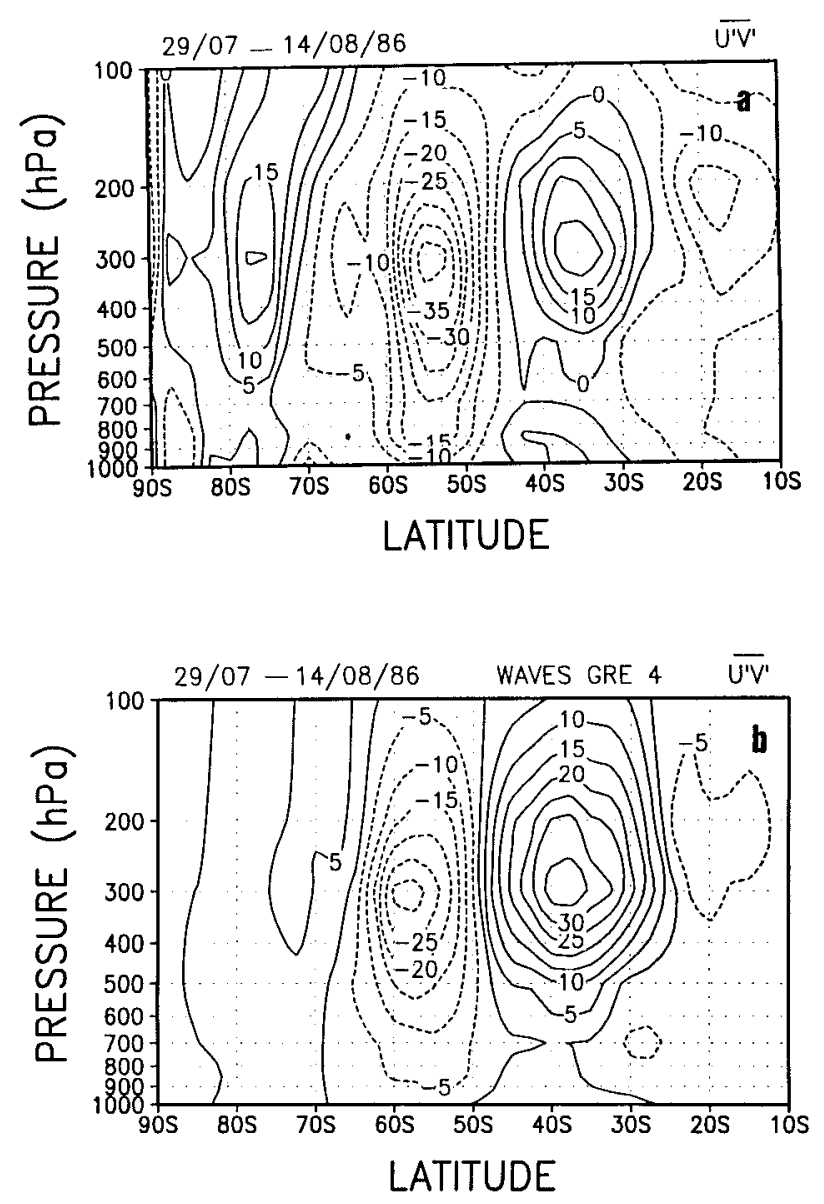

FIG. 12. Vertical distribution of mean momentum flux (in $\mathrm{m}^{2} \mathrm{~s}^{-2}$ ) for the period $29 \mathrm{Jul}-14$ Aug 1986 and for the longitude belt $75^{\circ}$ $165^{\circ} \mathrm{W}$ for (a) the total and (b) waves greater than wavenumber 4 . Negative values dashed.

a different longitude belt $\left(75^{\circ}-165^{\circ} \mathrm{W}\right)$ in the southeast Pacific during the long-lasting blocking event. In this region, the split jet structure appears even in the mean winter conditions (Fig. 10b).

Figure 11 shows the zonal wind profile over the longitude belt $75^{\circ}-165^{\circ} \mathrm{W}$ at $300 \mathrm{hPa}$. Also shown in this figure is the northward momentum transport $\overline{u^{\prime} v^{\prime}}$ by the eddies for the same longitude belt. Figure 11a shows the two quantities for the blocking event of 1986 and Fig. 11b shows the composite of the four blocking events mentioned earlier. It is seen in both Figs. 11a and $11 \mathrm{~b}$ that there is convergence of eddy momentum transport at the latitudes of the two jets (the subtropical jet at $25^{\circ}-30^{\circ} \mathrm{S}$ and the subpolar jet around $\left.70^{\circ} \mathrm{S}\right)$. There is a divergence of eddy momentum transport at the latitude of the minimum in the mean zonal wind at $45^{\circ}-50^{\circ} \mathrm{S}$. It can be inferred from Eq. (4) that at the latitudes of the two jets the zonal kinetic energy is maintained at the expense of eddy kinetic energy, whereas in the region of minimum of zonal wind, zonal kinetic energy is converted into eddy kinetic energy.
This shows that the eddies maintain the zonal wind structure over these longitudes $\left(75^{\circ}-165^{\circ} \mathrm{W}\right)$ including the split jet structure. Thus, in the case of blocking events over the southeast Pacific, eddies barotropically decelerate the westerlies near the split in the jet and thereby maintain the block. This picture is very different from the one noted by Trenberth (1986b) for the blocking in the New Zealand region. In his case Trenberth $(1986 b)$ noted that eddies are gaining kinetic energy from the zonal kinetic energy; that is, eddies are destroying the split jet structure. In our case the eddies are barotropically reinforcing the split jet structure. This raises the question, how are the eddies generated and maintained during the present blocking event? The eddies are very likely generated by the baroclinic processes associated with eddy heat transport. Before starting to discuss the eddy heat transport during the blocking event, let us examine the role of waves 1-4 in the transport of momentum. These waves are responsible for the structure of the split jet and the mean flow over the blocking region (see Figs. 7 and 8). Figures $12 \mathrm{a}$ and $12 \mathrm{~b}$ show, respectively, the total momentum transport by all eddies and by wavenumbers greater than wavenumber 4 . It can be noted that the northward momentum transport at the subtropical latitudes by the higher wavenumbers increased (Fig. 12b), whereas in the polar latitudes larger waves are important. Earlier, we noted that eddies maintain the subtropical and subpolar jets barotropically. Thus shorter waves in the subtropical latitudes and longer waves in the polar latitudes are important in maintaining the subtropical and subpolar jets (Fig. 12b).

In order to verify the baroclinic processes associated with the eddies during the blocking event, sensible heat transport is also calculated. We show the sensible heat transport by all eddies, eddies greater than wavenumber 4, and in the bandpass-filtered data of 3-7 days. The filter is applied by taking the running mean of 3 and 7 days and then subtracting them. Sensible heat transport by eddies greater than wavenumber 4 and in the frequency band of 3-7 days are isolated to see the contribution from the high-frequency part of the spectrum.

Figure 13 shows the transient eddy heat flux. Note the general poleward heat flux (negative value) near the blocking region, particularly in panels $b$ and c. This poleward heat transport together with the vertical zonal wind shear shows that the baroclinic processes are important for the generation and maintenance of eddies. Figure 14 shows the vertical cross section of the sensible heat transport by eddies over the longitudes $75^{\circ}-165^{\circ} \mathrm{W}$. From these figures it can be seen that there are two lowlevel maxima in the poleward heat flux, one at $35^{\circ} \mathrm{S}$ and the other at $70^{\circ} \mathrm{S}$. Also it can be noted that smaller-scale eddies are dominant in transporting heat at $35^{\circ} \mathrm{S}$ and larger-scale eddies are dominant at $70^{\circ} \mathrm{S}$. Strong heat transport in the lower stratosphere can be seen in Fig. 14a but not in Fig. 14b, showing that larger waves 

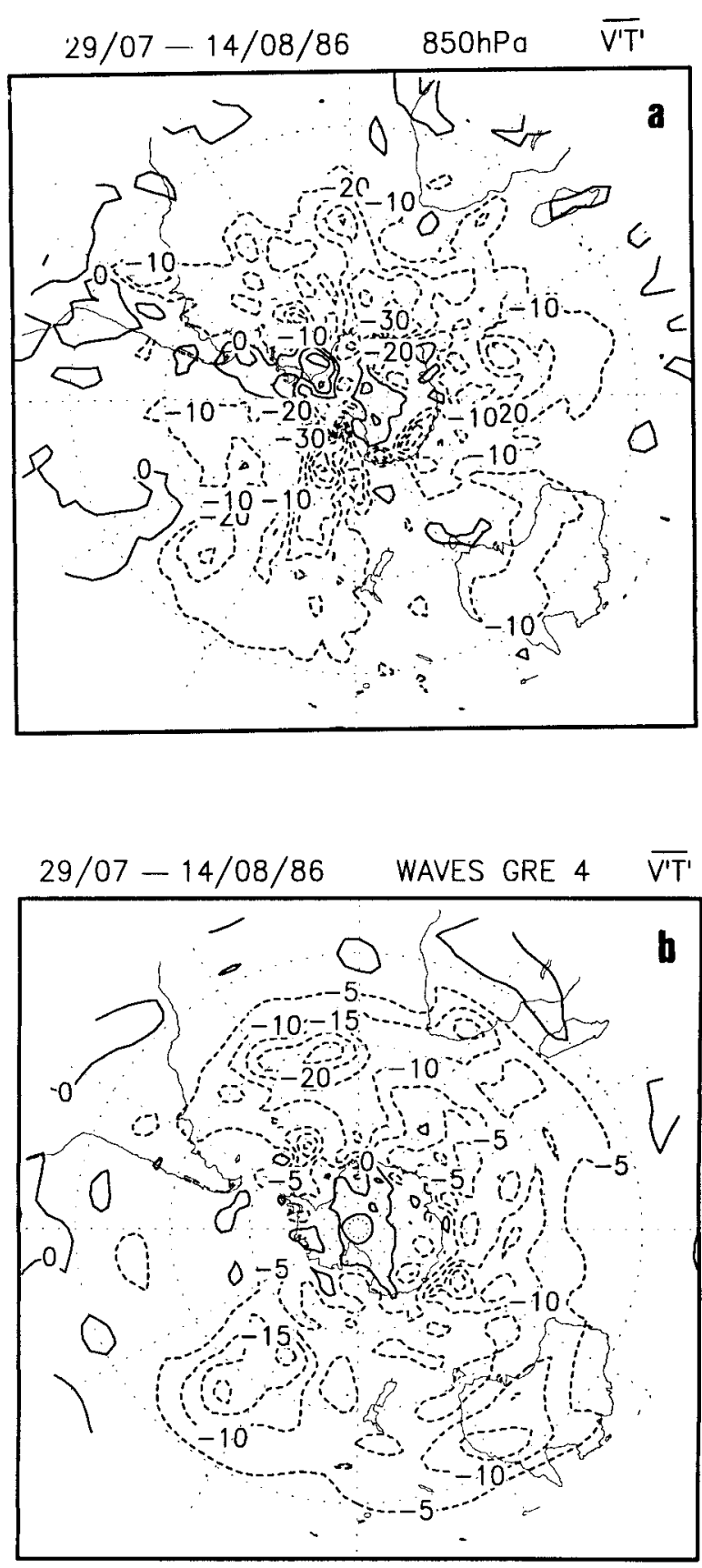

(wavenumbers 1-4) only propagate into the stratosphere (Charney and Drazin 1961).

Figure 15 shows the standard deviation of $v$ and $u$ $[\sigma(v)$ and $\sigma(u)]$ over the same longitude belt for the blocking period. These figures show two maxima at 300 $\mathrm{hPa}$. The third maximum in the polar latitudes at 300 $\mathrm{hPa}$ in $\sigma(u)$ is somewhat intriguing. This maximum is associated with strong polar easterlies that appeared at the end of the blocking period (figure not shown). From Figs. 13, 14, and 15, it can be inferred that the transient eddies are blocked from entering the region of the block-

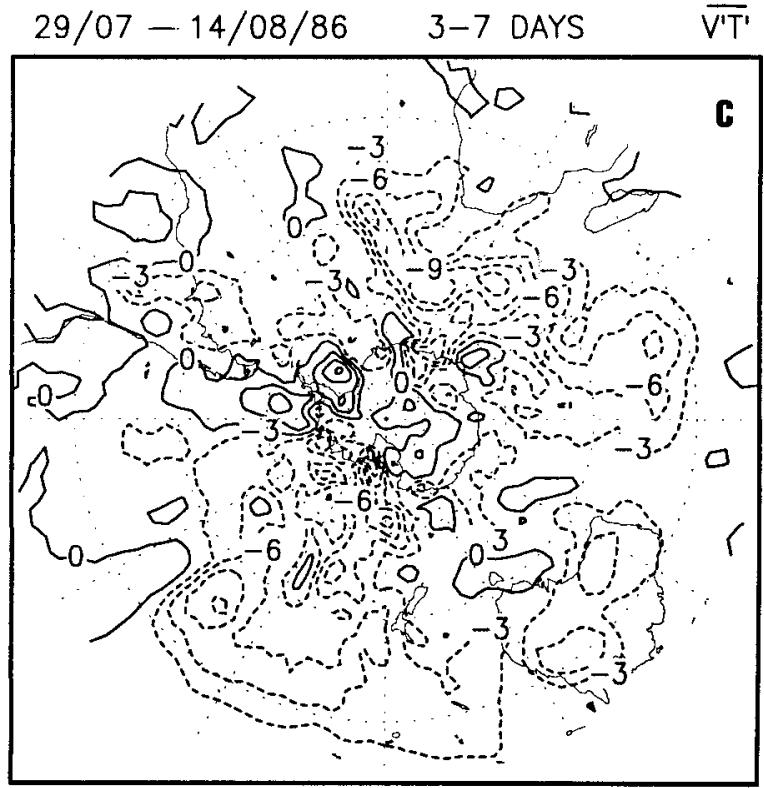

FIG. 13. Transient heat flux (in $\mathrm{m} \mathrm{s}^{-1} \mathrm{~K}$ ) at $850 \mathrm{hPa}$ for the period 29 Jul-14 Aug 1986 and for the longitude belt $75^{\circ}-$ $165^{\circ} \mathrm{W}$ for (a) the total, (b) waves greater than wavenumber 4, and (c) 3-7 days. ing high over the southeast Pacific (Fig. 2), and the wave activity is steered to the north and south following the split jet. Note that the maximum of low-level poleward heat flux at $35^{\circ}$ and $70^{\circ} \mathrm{S}$ (Fig. 14), the 300-hPa maximum in $\sigma(v)$ (Fig. 15), and the tendency for a double maximum in $\sigma(u)$ represent the model storm track configuration (Trenberth 1986b).

To further explore the role of eddies in the zonal wind, we calculated the (horizontal) barotropic component of $E$ at $300 \mathrm{hPa}$ given in Eq. (5). Figure 16 shows the horizontal vector component of Eq. (5) for 

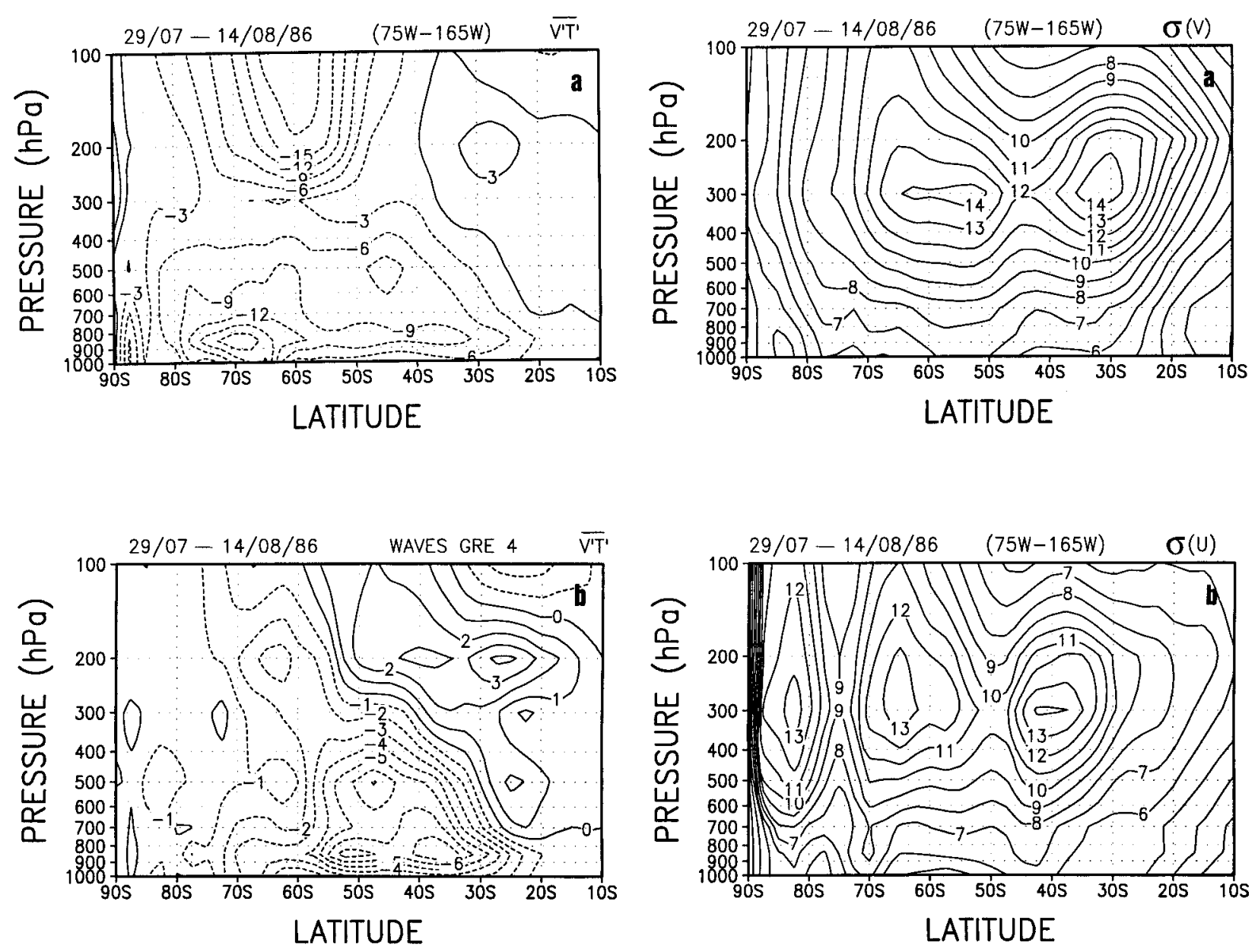

FIG. 15. Vertical distribution of standard deviation for the period $29 \mathrm{Jul}-14$ Aug 1986 and for the longitude belt $75^{\circ}-165^{\circ} \mathrm{W}$ for (a) meridional wind (in $\mathrm{m} \mathrm{s}^{-1}$ ) and (b) zonal wind (in $\mathrm{m} \mathrm{s}^{-1}$ ).

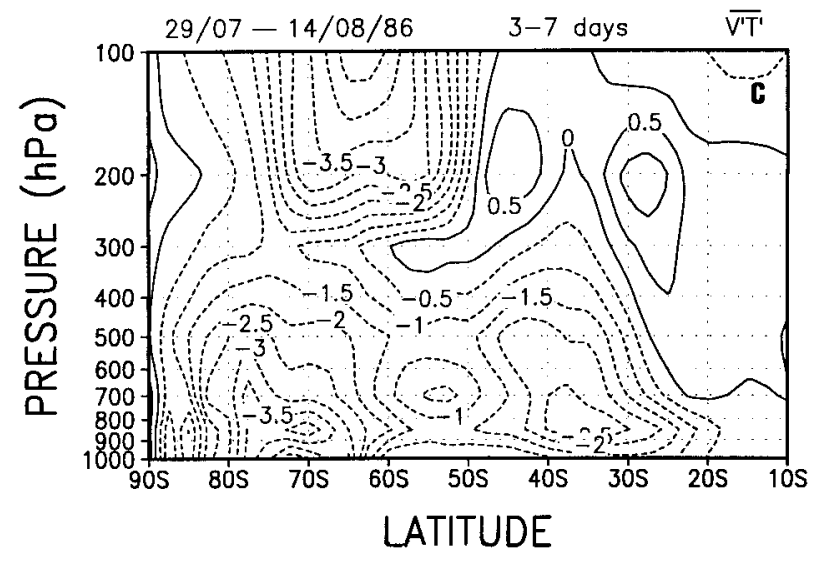

FIG. 14. Vertical distribution of transient heat flux (in $\mathrm{m} \mathrm{s}^{-1} \mathrm{~K}$ ) for the period $29 \mathrm{Jul}-14$ Aug 1986 and for the longitude belt $75^{\circ}-165^{\circ} \mathrm{W}$ for (a) the total, (b) waves greater than 4, and (c) 3-7 days. the period of blocking. Zonal wind accelerates in the region of divergence of this vector and decelerates in the region of convergence. For the region of the storm track in the southern Indian Ocean around $50^{\circ} \mathrm{S}$ the vectors are divergent, showing the eddies are accelerating the zonal wind. However in the region of blocking in the southeast Pacific the vectors are convergent, thereby decelerating the zonal wind and maintaining the block.

For a further diagnostic analysis of the role of eddies on the zonal flow, Fig. 17 shows the horizontal component (panel a), vertical component (panel b), and the total (panel c) of the E-P flux divergence in $\mathrm{m} \mathrm{s}^{-1}$ day $^{-1}$. It can be seen that the divergence of barotropic and baroclinic components reinforces in some areas and cancels in others. In the region of the main storm track in the South Atlantic and the south Indian Ocean around $50^{\circ} \mathrm{S}$, the two components are of opposite sign, but the baroclinic component dominates. While in the region of the blocking in the southeast Pacific both the compo- 
BAROTROPIC COMPONENT AT $300 \mathrm{hPa}$

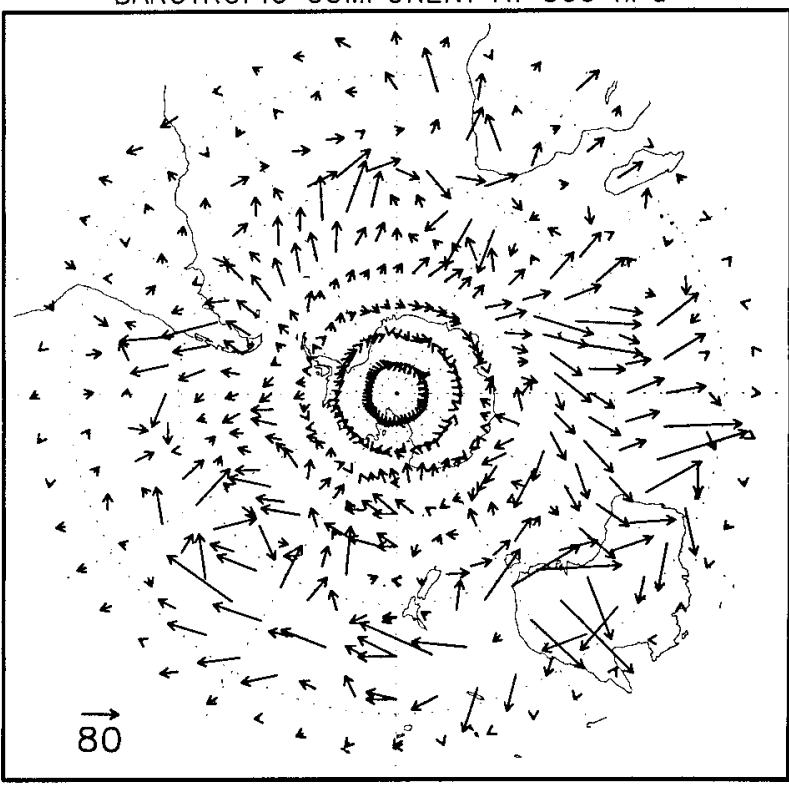

FIG. 16. Barotropic component of $E_{u}\left(\mathrm{in} \mathrm{m}^{2} \mathrm{~s}^{-2}\right.$ ) at $300 \mathrm{hPa}$ for the period 29 Jul-14 Aug 1986.

nents reinforce and a clear negative region is seen (Fig. $17 \mathrm{c})$. To the south and north of this region positive values are seen. The positive values in this region to the south of the block are strong (around $3 \mathrm{~m} \mathrm{~s}^{-1}$ day $^{-1}$ ). Thus the analysis of the E-P flux complements the inferences reached earlier while discussing Fig. 11. The eddies act to decelerate the zonal wind in the region of $75^{\circ}-165^{\circ} \mathrm{W}$ around $50^{\circ} \mathrm{S}$ and to accelerate it to the south and north of this region, thereby maintaining the split jet associated with the blocking.

\section{Summary and conclusions}

A detailed study of a long-lasting (29 July-14 August 1986) blocking event in a new region of blocking in the southeast Pacific is made. The effect of this block on the winter general circulation is very clear. There is a substantial increase in the amplitudes of wavenumbers 1, 2, and 3 during the blocking event in comparison with the normal winter when no block is formed. There are also large changes in the zonal wind (wavenumber 0). A composite of four cases of blocking in the southeast Pacific confirmed these results. This shows that the configuration of blocking is essentially a local phenomenon involving several waves. The local nature of the blocking phenomenon is emphasized by Mak (1991).

The blocking event in the southeast Pacific affected the mean flow and eddy characteristics. There is a split jet configuration with a subtropical jet to the north, a subpolar jet to the south, and a blocking high in the center. Transient eddies are steered to the north and south of the block. These characteristics are similar to those associated with the blocking in the usual New Zealand region (Trenberth 1986a). However, the amplitudes of wavenumbers 1, 2, and 3 seem to be much higher in the present case.

The blocking event of winter 1986 affected precipitation over South America. To the north of the block, the precipitation increased and over the region of the blocking it decreased. At some stations the rainfall anomalies were large fractions of the normal. The increase of precipitation to the north of the blocking high was associated with the deflection of transient eddies to the north of the block and the decrease to the south was due to the blocking high inhibiting ascending motion.

Diagnosis of barotropic energy conversion showed that the eddies maintain two branches of the jet (subtropical and subpolar jets), converting eddy kinetic energy into zonal kinetic energy. In the middle of the jets, at the location of the blocking high, eddies gain kinetic energy at the expense of zonal kinetic energy, thus maintaining low values of zonal wind.

The local E-P flux diagnostics indicated that the transient eddies act to decelerate the westerlies in the region of the split jet and accelerate westerlies to the north and south of the split jet. The deceleration in the region of the blocking high acts to counter the tendency of the block to move downstream under the influence of mean flow advection. The poleward heat transport by the eddies together with the barotropic energy exchanges noted earlier supports the view that transient eddies are maintained by baroclinic processes.

The above results are compatible with those of Shutts (1983) and Illari (1984) for the Northern Hemisphere blocking. Shutts (1983) put forth the idea of an "eddy straining" mechanism. He suggested that the transient eddies are strained and undergo stretching in the north-south direction and compressed in the eastwest direction. This would lead to momentum flux and conversion of energy to the blocked flow. Illari (1984) suggests that the eddy forcing acts to prevent the downstream movement of the blocking high. Mak (1991) showed the existence of such a mechanism through the analysis of local energetics of a blocking event. There are some similarities in the results of the present study and those of Trenberth (1986a,b) for a blocking episode in the New Zealand region. The role of eddies as inferred by Eliassen-Palm diagnostics in both cases is to maintain the split jet in the two regions (southeast Pacific and near New Zealand) is similar. However there is an important difference. In the present case we noted eddies barotropically maintain the split jet structure of the zonal wind, whereas in Trenberth's case he noted that eddies gain kinetic energy at the expense of zonal kinetic energy; that is, eddies try to destroy the split jet structure. 
div. barotropic comp. of E-P flux

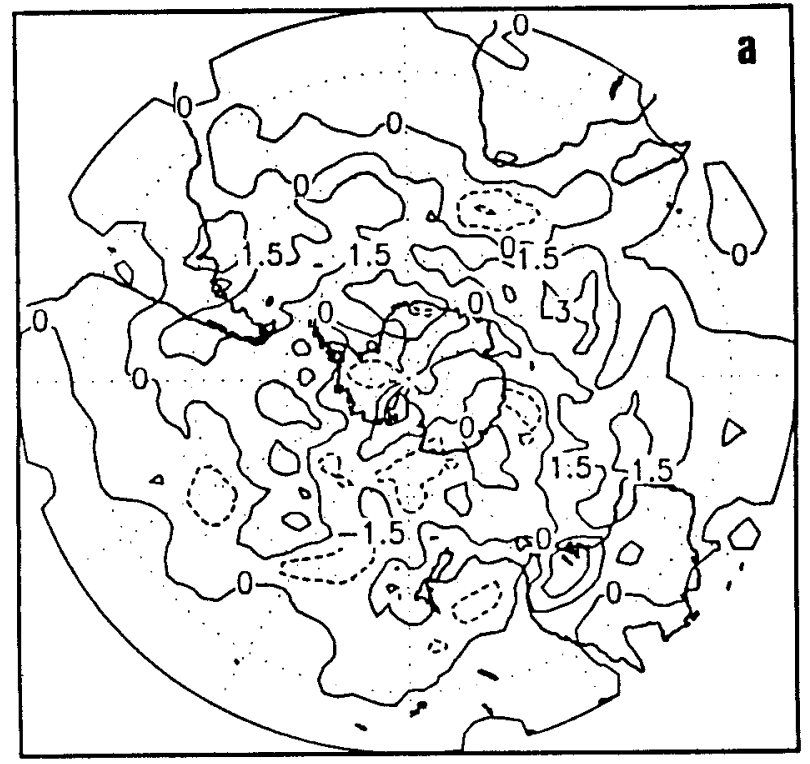

div. baroclinic comp. of E-P flux

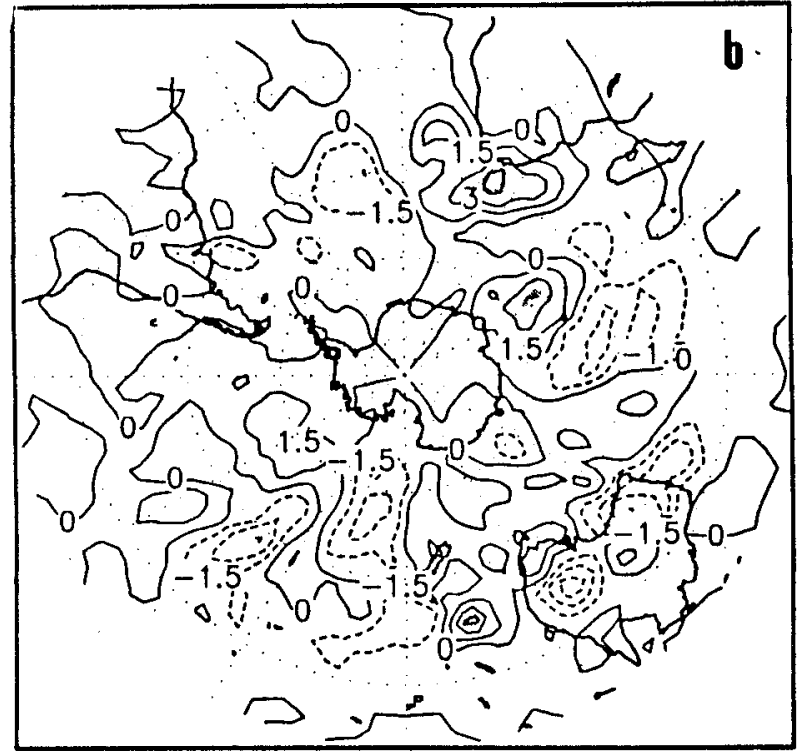

Acknowledgments. This work formed part of the $\mathrm{Ph} . \mathrm{D}$. thesis of the first author and was done primarily at CPTEC. Thanks are due to Dr. C. A. Nobre for the facilities and interest in this work. Thanks are also due to official reviewers for useful suggestions.

\section{REFERENCES}

Baines, P. G., 1983: A survey of blocking mechanisms, with application to the Australian region. Aust. Meteor. Mag., 31, 27-36. div. of total E-P flux

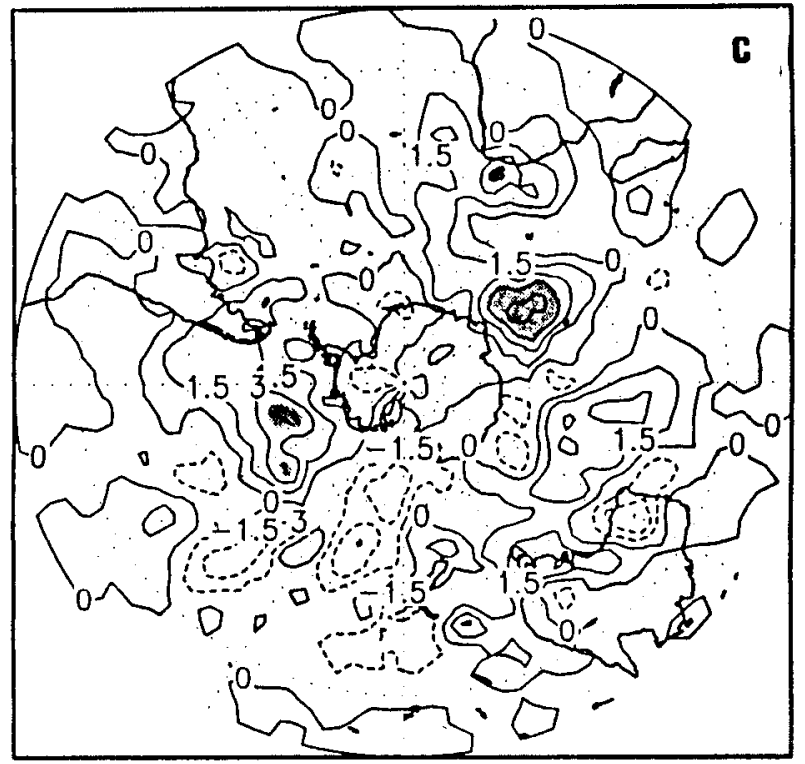

FIG. 17. Divergence of $E\left(\mathrm{~m} \mathrm{~s}^{-1}\right.$ day $\left.^{-1}\right)$ at $300 \mathrm{hPa}$ for the period 29 Jul-14 Aug 1986 for (a) horizontal (barotropic) E$\mathrm{P}$ flux divergence, (b) vertical (baroclinic) E-P flux divergence, and (c) the total E-P flux divergence.
Bengtsson, L. M., 1986: Four-dimensional data assimilation. Int. Conf. on the Results of the Global Weather Experiment and Their Implications for the World Weather Watch, WMO/TD No. 107, GARP Publ. 26, 187-216.

Berbery, E. H., and M. N. Núñez, 1989: An observational and numerical study of blocking episodes near South America. J. Climate, 2, 1352-1361.

Bluestein, H. B., 1993: Synoptic-Dynamic Meteorology in Midlatitudes. Vol. II, Observations and Theory of Weather Systems, Oxford University Press, 594 pp.

Charney, J. G., and P. G. Drazin, 1961: Propagation of planetary- 
scale disturbances from the lower into the upper atmosphere. $J$. Geophys. Res., 66, 83-109.

Coughlan, M. J., 1983: A comparative climatology of blocking action in the two hemispheres. Aust. Meteor. Mag., 31, 3-13.

Elliot, R. D., and T. B. Smith, 1949: A study of the effects of large blocking highs on the general circulation in the Northern Hemisphere westerlies. J. Meteor., 6, 67-85.

Hollingsworth, A., D. B. Shaw, P. Lönnberg, L. Illari, K. Arpe, and A. J. Simmons, 1986: Monitoring of observation and analysis quality by a data assimilation system. Mon. Wea. Rev., 114, 861879.

Hoskins, B. J., I. N. James, and G. H. White, 1983: The shape, propagation and mean-flow: Interaction of large-scale weather systems. J. Atmos. Sci., 40, 1595-1612.

Illari, L., 1984: A diagnostic study of the potential vorticity in a warm blocking anticyclone. J. Atmos. Sci., 41, 3518-3526.

Kalnay, E., and Coauthors, 1996: The NCEP/NCAR 40-Year Reanalysis Project. Bull. Amer. Meteor. Soc., 77, 437-471.

Kalnay-Rivas, E., and L. O. Merkine, 1981: A simple mechanism for blocking. J. Atmos. Sci., 38, 2077-2091.

Lejenäs, H., 1984: Characteristics of Southern Hemisphere blocking as determined from a long time series of observational data. Quart. J. Roy. Meteor. Soc., 110, 967-979.

— blocking as determined from a long time series of observational data. Tellus, 35A, 350-362.

— blocking. Mon. Wea. Rev., 120, 2821-2830.

Mak, M., 1991: Dynamic of an atmospheric blocking as deduced from its local energetics. Quart. J. Roy. Meteor. Soc., 117, 477493.

Marques, R. F. C., 1996: Southern Hemisphere blocking (in Portuguese). Ph.D. thesis, Instituto Nacional de Pesquisas Espaciais, São José dos Campos, SP, Brazil, 158 pp. [Available from INPE, C.P. 515 São José dos Campos, São Paulo, Brazil.]

Plumb, A., 1986: Three-dimensional propagation of transient quasigeostrophic eddies and relationship with the eddy forcing of the time-mean flow. J. Atmos. Sci., 43, 1657-1678.

Rex, D. F., 1950a: Blocking action in the middle troposphere and its effects upon regional climate I-An aerological study of blocking action. Tellus, 2, 196-211.

, 1950b: Blocking action in the middle troposphere and its effects upon regional climate II-The climatology of blocking action. Tellus, 2, 275-301.

Rutllant, J., and H. Fuenzalida, 1991: Synoptic aspects of the central Chile rainfall variability associated with the Southern Oscillation. Int. J. Climatol., 11, 63-76.

Shutts, G. J., 1983: The propagation of eddies in diffluent jetstreams: Eddy vorticity forcing of blocking flow fields. Quart. J. Roy. Meteor. Soc., 109, 737-761.

Sinclair, M. R., 1996: A climatology of anticyclones and blocking for the Southern Hemisphere. Mon. Wea. Rev., 124, 245-263.

Taljaard, J. J., 1972: Synoptic meteorology of the Southern Hemisphere. Meteorology of the Southern Hemisphere, Meteor. Monogr., No. 35, Amer. Meteor. Soc., 139-213.

Tibaldi, S., and F. Molteni, 1990: On the operational predictability of blocking. Tellus, 42A, 343-365.

_, E. Tosi, A. Navarra, and L. Pedulli, 1994: Northern and Southern Hemisphere seasonal variability of blocking frequency and predictability. Mon. Wea. Rev., 122, 1971-2003.

Trenberth, K. E., 1986a: The signature of a blocking episode on the general circulation in the Southern Hemisphere. J. Atmos. Sci., 43, 2061-2069.

_ 1986b: An assessment of the impact of transient eddies on the zonal flow during a blocking episode using localized EliassenPalm flux diagnostics. J. Atmos. Sci., 43, 2070-2087.

— in the Southern Hemisphere: Preprints, First Int. Conf. on Southern Hemisphere Meteorology, São José dos Campos, SP, Brazil, Amer. Meteor. Soc., 73-76.

_, and K. C. Mo., 1985: Blocking in the Southern Hemisphere. Mon. Wea. Rev., 113, 3-21.

— , and J. G. Olson, 1988: An evaluation and intercomparison of global analyses from the National Meteorological Center and the European Centre for Medium Range Weather Forecasts. Bull. Amer. Meteor. Soc., 69, 1047-1057.

van Loon, H., 1956: Blocking action in the Southern Hemisphere: Part I. Notos, 5, 171-175.

_ J. J. Taljaard, R. L. Jenne, and H. L. Crutcher, 1971: Climate of the upper air: Southern Hemisphere. Vol II, Zonal geostrophic winds. NCAR Tech. Note TN/STR-57, 38 pp.

World Meteorological Organization, 1986: Monthly Climatic Data for the World. Vol. 39, No. 8.

Wright, A. D., 1974: Blocking action in the Australian region. Department of Science Bureau of Meteorology, Tech. Rep. 10, 29 pp. 